\title{
O DESEMPENHO ESCOLAR NA VOZ DOS ATORES DE ESCOLAS PÚBLICAS CATARINENSES
}

Aline Dallazem

Vera Rejane Coelho

Com o objetivo de ampliar a discussão e a análise sobre a educação no país a Coordenação de Aperfeiçoamento de Pessoal de Nível Superior (Capes) e o Instituto Nacional de Estudos e Pesquisas Educacionais Anísio Teixeira (INEP) têm desenvolvido programas específicos voltados à educação básica e à formação docente inicial e continuada. Dentre esses programas destacamos o Observatório da Educação que, desde o ano de 2006, vem fomentando pesquisas nessa área.

Sendo assim, a presente pesquisa tem origem no Observatório de Educação e foi desenvolvida pelas instituições: Universidade Estadual de Campinas (Unicamp),Universidade do Oeste Paulista (Unoeste) e Universidade do Planalto Catarinense (Uniplac), com objetivo de conhecer os fatores determinantes para o alto e o baixo desempenho de alunos de turmas de $5^{\circ}$ e $9^{\circ}$ anos do ensino fundamental de Campinas/SP, Presidente Prudente/SP, Lages/SC e Curitibanos/SC; cidades nas quais estas universidades estão inseridas.

Este artigo refere-se exclusivamente aos resultados das investigações realizadas nas cidades de Lages e Curitibanos (SC), portanto, foram parceiras doze (12) escolas públicas estaduais de Lages e quatro (04) de Curitibanos e suas respectivas Gerências Regionais de Educação. As escolas que participaram do projeto foram selecionadas tendo como critério o desempenho dos alunos na Prova Brasil de 2009, bem como o IDEB das escolas do mesmo ano. Das 16 escolas selecionadas, sete tiveram o melhor desempenho na Prova Brasil e no IDEB, quatro apresentaram o pior desempenho e cinco escolas demonstraram alto desempenho no $5^{\circ}$ ano e baixo desempenho no $9^{\circ}$ ano. Os critérios que determinaram o melhor ou o pior desempenho são aqueles que mais se aproximam ou mais se afastam da média do estado de Santa Catarina.

Por sua vez, os lócus da pesquisa foram as 16 escolas mencionadas acima e o público-alvo foi composto pelos professores de Língua Portuguesa e Matemática, alunos e pais de alunos do $5^{\circ}$ e do $9^{\circ}$ ano do ensino fundamental. Metodologicamente, a pesquisa foi de caráter exploratório, com fundamentação bibliográfica e documental e pesquisa de campo. Como instrumentos de coleta dos dados foram utilizados questionários com perguntas aberta e fechadas, além de um instrumento com dados que foram observados nas escolas que, posteriormente, foram transcritos e analisados. Portanto, trata-se de uma pesquisa com análises quali e quantitativas. 
O fato é que o levantamento de dados estatísticos (SIMON, 2013)e as análises das diferentes variáveis que interferem no desempenho escolar têm possibilitado às escolas a definição-ações próprias para a resolução dos problemas específicos de cada uma. Dessa forma, o que propomos aqui é a análise dessas variáveis, bem como dos dados estatísticos compilados a partir das respostas fechadas dos professores, alunos e pais de alunos.

\section{A FAMÍLIA E A ESCOLA: EXPECTATIVAS E OLHARES}

A relação família e escola é objeto de reflexão em inúmeras pesquisas (estudos), nos mais diversos contextos. Autores buscam equacionar as diferentes interpretações que uma instituição tem da outra e articular o melhor caminho para ambas. No entanto, é fato que a primeira forma de educar aprendida e vivenciada pelos homens é a observação e a repetição de padrões desenvolvidos na convivência familliar. Esse aprendizado será responsável pela formação do caráter da criança, e a escola será a responsável pela continuidade dessa formação de um sujeito pertencente a uma sociedade.

Se a aprendizagem começa na base familiar onde os pais formam o caráter, os valores, o respeito pels leis, a hierarquia; agora, é a vida escolar que vai complementar esse crescimento, ao informar, transmitir conhecimentos, reforçar o sentido de cidadania, dando esforços às responsabilidades sociais por meio da vida acadêmica (CHRAIM, 2009, p. 45).

Conforme a autora, a escola dá continuidade à formação iniciada pelos pais e, por isso, se torna tão necessária a compreensão de como esse processo ocorre no contexto pesquisado. Dessa forma,neste subcapítulo serão apresentados os resultados das análises dos questionários respondidos pelos pais dos alunos de turmas de $5^{\circ}$ e $9^{\circ}$ anos do ensino fundamentalde escolas de baixo e alto desempenho, das cidades de Lages e Curitibanos, estado de Santa Catarina. Além disso, serão investigadas as possíveis causas para os índices alcançados nos dois contextos das avaliações externas, da Prova Brasil e do Censo Escolar 2009.

Em Lages, foram pesquisados 218 pais de alunos do $5^{\circ}$ ano de sete escolas de alto desempenho e 137 pais de alunos de quatro escolas de baixo desempenho. Em relação aos alunos do $9^{\circ}$ ano, foram pesquisados 276 pais de alunos de oito escolas de alto desempenho e 159 pais de alunos de quatro escolas de baixo desempenho.

Em Curitibanos, foram pesquisados 103 pais de alunos do $5^{\circ}$ ano de uma escola de alto desempenho e 117 pais de alunos de duas escolas de baixo desempenho. Em relação aos alunos do 
$9^{\circ}$ ano, foram pesquisados 102 pais de alunos de uma escola de alto desempenho e 114 pais de alunos de 3 escolas de baixo desempenho.

De tal modo, foram analisados oito contextos assim divididos:

1. Cidade de Lages - Escola de Alto Desempenho - $5^{\circ}$ ano;

2. Cidade de Lages - Escola de Baixo Desempenho - 5º ano;

3. Cidade de Lages - Escola de Alto Desempenho - $9^{\circ}$ ano;

4. Cidade de Lages - Escola de Baixo Desempenho - $9^{\circ}$ ano;

5. Cidade de Curitibanos - Escola de Alto Desempenho - $5^{\circ}$ ano;

6. Cidade de Curitibanos - Escola de Baixo Desempenho - $5^{\circ}$ ano;

7. Cidade de Curitibanos - Escola de Alto Desempenho - $9^{\circ}$ ano;

8. Cidade de Curitibanos - Escola de Baixo Desempenho - $9^{\circ}$ ano.

Numa pesquisa realizada por Albernaz, Ferreira e Franco (2002) sobre a qualidade e equidade na educação fundamental brasileira, vários dados foram levantados sugerindo que cerca de 80\% da variância em desempenho médio entre as escolas de baixo e alto desempenho deve-se às diferenças na composição socioeconômica de seus alunos. Esta condição pode ser revertida à medida que esses alunos possam encontrar os mesmos estímulos das famílias, o acesso a materiais didáticos e a vivências positivas que aproximem o aluno não só das informações, mas do conhecimento sistematizado historicamente e também do que se produz culturalmente na contemporaneidade.

Diante desse cenário, passamos a apresentar alguns dados referentes ao perfil dos pais destes alunos para entender melhor o contexto educacional e familiar em que eles se inserem.Em todos os contextos,o maior índice de idade dos pais se encontra na faixa etária compreendida entre os 35 e os 44 anos de idade, no entanto, a maioria das mães está entre 25 e 34 anos.

Quanto à situação de emprego, tantos os pais de alunos de escolas de alto e de baixo desempenho se encontram empregados (entre 50 e 60\%) ou são autônomos (12 a 20\%). O mesmo se aplica à condição da mãe, empregada (entre 39 e 50\%) e autônoma (12\% a 15\%).

Os dados apontam tanto para os alunos de alto como para os de baixo desempenho que possivelmente estão em companhia dos pais somente no período noturno. Isso significa que parte do dia eles ficam na escola e a outra parte ficam sozinhos ou com parentes. 
Nos dados referentes ao nível de escolaridade dos pais, observa-se que, em geral, os pais dos alunos do $5^{\circ}$ e $9^{\circ}$ ano de escolas de alto desempenho, na cidade de Lages, possuem Ensino Médio completo (21\%)e nas escolas de baixo desempenho este percentual cai para 14\%,em relação aos pais de alunos do $9^{\circ}$ ano, mas para os pais de alunos de $5^{\circ}$ ano permanece o mesmo índice (21\%). Destaca-se que menos de $5 \%$ dos pais de alunos de Lages possuem Ensino Superior completo.

Na cidade de Curitibanos, 34\% dos pais de alunos de escolas de alto desempenho, $5^{\circ}$ e $9^{\circ}$ ano, concluiu o Ensino Médio, enquanto nas escolas de baixo desempenho apenas 18\% concluiu este nível de ensino. Da mesma forma, 16\% dos pais de alunos de escola de alto desempenho possuem formação em Ensino Superior, enquanto apenas 3\% dos pais de alunos de escolas de baixo desempenho possuem ensino superior completo. Este índice é muito semelhante nos casos de pais de alunos do $5^{\circ}$ e $9^{\circ}$ ano.

Representam 17\% do total, as mães de alunos de escolas de alto desempenho que possuem Ensino Superior completo em comparação aos 2\% das mães de alunos de escolas de baixo desempenho com a mesma formação.

Observa-se que há uma significativa diferença entre os contextos Curitibanos e Lages quando o assunto é a formação em Ensino Superior, sendo que em Curitibanos o índice atinge 17\%, enquanto em Lages não chega a 5\%. Este dado merece melhor análise ao consideramos que a cidade de Lages demanda de maior oferta, pois possui 02Universidades, 01 Centro Universitário, 01 Instituto Federal de Santa Catarina (IFSC), 01 polo da Universidade Federal de Santa Catarina (UFSC) e diversos polos de instituições de ensino superior (IES) na modalidade à distância, com programas de financiamento e bolsa disponíveis em diferentes formas, oportunizando assim o acesso ao ensino superior da maioria da população, enquanto Curitibanos possui apenas 02 universidades.

De fato, o número de habitantes é importante, sendo que em Curitibanos é de 37.748, e em Lages são 156.727 habitantes (IBGE, 2017). No entanto, a proporção de oferta e demanda estaria equilibrada, considerando os contextos, ficando Curitibanos com a menor oferta?

Então, qual seria o motivo para este baixo índice na cidade de Lages?Por que menos de 5\% dos pais destes alunos possuem formação em ensino superior? Seria um aspecto cultural, regional? Faltaria motivação? E esta desmotivação desenvolve alguma influência no interesse dos filhos em estudar e/ou dar continuidade aos seus estudos? 
A esse respeito, um estudo realizado pelos pesquisadores Ramos e Reis (2008) do Instituto de Pesquisa Econômica Aplicada (Ipea), sobre a escolaridade dos pais e os retornos à educação no mercado de trabalho aponta que

[...] não apenas a mobilidade educacional e de rendimentos é baixa, mas também que o diferencial de rendimentos de filhos de pais com educação mais elevada em relação a filhos cujos pais tiveram baixo nível de educação depende, positivamente, dos anos de estudo do trabalhador. Ou seja, quando comparados dois indivíduos com a mesma escolaridade, para cada ano adicional de estudo o diferencial de rendimentos tende a aumentar se os pais desses trabalhadores alcançaram níveis melhores de escolaridade, o que significa dizer que os retornos da educação crescem de acordo com a escolaridade dos pais.

Há ainda a pesquisa realizada por Rezende e Candian (2012) que procuraram relacionar a participação da família na escola com o desempenho dos alunos, aponta que: “As características das famílias, como escolaridade dos pais e existência de livros em casa, são o que mais afetam os resultados do desempenho em Matemática” (REZENDE; CANDIAN, 2012, p. 15).

No entanto, outro estudo realizado por pesquisadoras da Universidade Estadual de Campinas que buscou identificar e analisar diferenças entre as percepções de autoeficácia acadêmica e o uso de estratégias de estudo e aprendizagem em aulas de língua portuguesa de estudantes do ensino médio de escolas públicas, de acordo com o nível de estudo dos pais e das mães, destacou como principais resultados que:

(1) o nível de estudo das mães e dos pais não exerceram influência de modo padronizado nas percepções de Autoeficácia Acadêmica. Isso parece indicar que um estudante cujo pai não terminou o ensino fundamental pode perceber-se como autoeficaz academicamente; e (2) o nível de estudo das mães e dos pais não demonstraram diferenças entre o uso de Estratégias de Estudo e de Aprendizagem, de modo que se faz necessário estimular o desenvolvimento destas nos ambientes escolares, independentemente do histórico educacional dos pais (GUERREIROCASANOVA; DANTAS; AZZI, 2011, p. 51).

Embora considerando os diferentes resultados e interpretações entre os estudos apresentados é possível dizer que nessa pesquisa há uma relação significativa nesse aspecto. Os pais dos alunos de escola de alto desempenho em ambas as cidades analisadas, possuem maior nível de escolaridade e esse cenário parece influenciar na motivação de seus filhos em permanecer na escola e se interessar pelos conhecimentos construídos nela. 
Já no que se refere à renda familiar, na maioria das famílias dos alunos de escolas de alto desempenho de Curitibanos ela é de 2 a 6 salários mínimos e nas escolas de baixo desempenho entre 1 e 1,5 salário mínimo. No caso de Lages, a maioria das famílias dos alunos de escolas de alto desempenho têm renda entre 1 e 1,5 salários mínimos enquanto as de baixo desempenho recebem apenas 1 salário mínimo. Talvez este seja um fator relacionado às formas de trabalho e formação/preparação para o mesmo, pois podemos observar que os pais de alunos das escolas de Curitibanos possuem maior formação em ensino superior, por exemplo, do que os pais de alunos de Lages.

Ao final da análise dos dados da cidade de Curitibanos, surge uma relação muito forte entre as escolas de alto desempenho, as famílias de maior renda e os pais com formação em ensino superior. Em Lages, esta relação não fica tão evidenciada, até porque a própria renda familiar e a formação dos pais é similar nos dois casos: alunos de escolas de alto e baixo desempenho.

Quando questionados sobre receberem informações da escola referente ao progresso do seu filho, cerca de $70 \%$ dos pais dos oito contextos apontaramque recebem estas informações. No entanto, percebe-se que no caso dos alunos do $5^{\circ}$ ano, tanto em Lages quanto em Curitibanos, o retorno aos pais sobre o progresso dos filhos é maior se comparado ao retorno recebido pelos pais dos alunos do $9^{\circ}$ ano.

Esta pesquisa aponta que, em geral, os pais tendem a acompanhar melhor as lições de casa e atividades da escola quando os filhos ainda estão nos anos iniciais. Da mesma forma, a pesquisa traz que, os pais dos alunos de $5^{\circ}$ ano, de Lages e Curitibanos, se apresentam mais satisfeitos com a qualidade da escola, que os pais de alunos de $9^{\circ}$ ano. Isto ocorre nas escolas de alto e baixo desempenho, da mesma forma.

Em torno de $84 \%$ dos pais dos alunos do $5^{\circ}$ ano, em todos os contextos, consideram que seu filho gosta da escola em que estuda. Esse índice cai para 55\% quando se trata de alunos do $9^{\circ}$ ano. Essa espécie de desencantamento, com o passar dos anos, pode ser reflexo da insatisfação do aluno com o seu rendimento escolar, ou com a metodologia de ensino utilizada nas escolas, ou ainda com outras questões. O fato é que tal desinteresse pode ter origem em diversas fontes, as quais essa pesquisa não pode aprofundar da forma necessária. Entretanto, tornou-se evidente que há desmotivação tanto de pais quanto de alunos conforme aumentam os anos de permanência na escola e que isso se aplica a todos os contextos pesquisados.

Os pais dos alunos do $5^{\circ}$ ano de escolas de alto e baixo desempenho consideram que seus filhos gostam de seus professores (85\%), em Curitibanos e Lages. Já no caso de alunos do $9^{\circ}$ ano, 
apresenta-se um número menor. Em Lages, em torno de 45\% dos alunos de escolas de alto e baixo desempenho parecem gostar de seus professores, segundo a resposta de seus pais. Por sua vez, em Curitibanos, 56\% dos pais de alunos de escola de baixo desempenho dizem que seus filhos gostam dos professores, no entanto, apenas 29\% dos pais de alunos de escolas de alto desempenho têm a mesma percepção.

Interessante esta análise se observarmos que os pais mais insatisfeitos, de forma geral, são justamente aqueles cujos alunos estudam em escolas que atingiram alto desempenho nas avaliações externas, na cidade de Curitibanos. Poderíamos relacionar o grau de criticidade dos pais dos alunos do $9^{\circ}$ ano de escolas de alto desempenho em Curitibanos à sua formação, por exemplo, sendo que estes compõem a parcela de pais com maior índice de formação em ensino superior, e que, talvez por isso, embora a escola esteja alcançando bons índices, consideram que a mesma ainda pode melhorar.

Segundo Dessen e Polônia (2007, p. 22) “a família e a escola emergem como duas instituições fundamentais para desencadear os processos evolutivos das pessoas, atuando como propulsoras ou inibidoras do seu crescimento físico, intelectual, emocional e social”. Nesse sentido, observamos que a relação da família com a escola e o envolvimento dos pais na educação escolar dos filhos vêm interferindo de forma significativa no seu desempenho.

Com relação aos processos pedagógicos de responsabilidade das escolas apresentam-se os seguintes percentuais: chamar para reunião informativa sobre os filhos (média de66\% alto e de 77\% baixo); chamar para a escola quando há problema (média de 68\% alto e de 66,4\% baixo). Para os pais de alto e baixo desempenho faltam informações sobre o planejamento da escola (média de32\% alto e de 33\% baixo), mas os pais de escolas de baixo e alto desempenho percebem que a escola se importa com a falta dos alunos (média de 42\%). Na pesquisa desenvolvida por Jacomini (2010, p. 204), a autora considera que a participação e o acompanhamento dos pais na vida escolar dos filhos se apresentam como “[...] elementos fundamentais para a aprendizagem das crianças”.

Observa-se diferença em relação à participação dos pais nas atividades da escola, sendo que nas escolas de alto desempenho, a participação dos pais é um pouco maior. Porém, o que chama a atenção é que a participação de pais de alunos do $9^{\circ}$ ano é quase que estritamente em reuniões de pais, descartando a participação em festas, campeonatos esportivos ou passeios.

Os pais de alunos do $5^{\circ}$ ano, por outro lado, costumam participar das reuniões de pais e das Datas Comemorativas. O fato é que alunos nessa idade escolar costumam se envolver mais nas atividades da escola e, com eles, seus pais. 
Quando perguntados sobre como participaram da vida escolar de seus filhos, a maioria dos pais respondeu que participa indo às reuniões da escola (variância entre 64\% a 82,1\% em escolas de baixo desempenho, e variância entre 54\% a 89,3\% em escolas de alto desempenho) e também dizem participar conversando com seu filho a respeito (variância entre 55\% a 73\% em escolas de baixo desempenho, e variância entre 59\% a 85,4\% em escolas de alto desempenho).

Também relatam acompanhar as lições de casa e conversarem com os professores sobre seus filhos. Nesse caso, os pais de alunos do $5^{\circ}$ ano (em torno de 67,2\% a 85,4\%) costumam conversar mais com os professores que os pais de alunos de $9^{\circ}$ ano (em torno de $28 \%$ a 48\%), independentemente da escola de alto ou baixo desempenho. Os pais de alunos de escolas de alto desempenho (entre 59\% a 85\%) parecem conversar mais com seus filhos sobre a escola do que os pais de alunos de escolas com baixo desempenho (entre 55\% a 73\%), no entanto a participação nas reuniões aparece em números muito similares.

Indicar que a questão da qualidade do ensino está associada à presença dos pais na escola é complexo, pois o índice de participação dos pais em ambas escolas é muito similar, havendo um caso inclusive em que os pais de escolas de baixo desempenho participam mais do que os de alto desempenho, no caso de Lages, no $9^{\circ}$ ano, por exemplo. Talvez, justamente na tentativa de entender melhor o processo e tentar reverter o quadro de aprendizagem em que se encontra seu filho.

O que parece estar mais relacionado a esta qualidade é a participação dos pais no processo de formação como um todo, no acompanhamento diário das lições de casa, no diálogo com o filho e com seus professores sobre seu desenvolvimento, ações essas que ocorrem em diferentes espaços que não somente os das reuniões de pais.

Evidenciou-se nesta pesquisa que a aproximação e o acompanhamento dos pais no processo de formação de seus filhos podem estimulá-los a se dedicarem mais e melhor aos estudos.Assim, corroboramos com Chraim (2009, p. 60) quando diz que,"Somente com pais e professores comprometidos com o futuro de toda uma geração é que poderemos colaborar para uma nação mais justa e equilibrada”.

\section{PROFESSORES E ALUNOS: VISÃO E ATUAÇÃO}

Toda relação torna-se simples ou complexa conforme a articulação entre as partes que a estabelecem. Sendo assim, essa pesquisa possibilitou algumas análises no sentido de compreender quais itens e relações podem fazer a diferença no sucesso escolar. 
Para iniciar, retrataremos brevemente o perfil dos professores envolvidos nesta pesquisa. Todos os professores participantes da cidade de Curitibanos possuem ensino superior, na cidade de Lages o contexto é parecido, apenas 3\% cursou somente o Magistério. Em Curitibanos os professores das escolas de alto e baixo desempenho, em geral, estão na faixa etária entre 40 e 49 anos; em Lages esta mesma faixa etária compreende a maioria dos professores das escolas de alto desempenho, já nas escolas de baixo desempenho a idade predominante é menor permanecendo na faixa de 30 a 39 anos.

Em ambos os casos, a maioria dos professores já está formada há mais de 8 anos e, predominantemente, (mais de 80\%) esses profissionais cursaram o ensino superior em instituição de ensino privada, especificamente em universidade e em segundo caso, em faculdades isoladas. Grande parte destes professores leciona há mais de 10 anos, o que significa que parte deles iniciou o trabalho docente, quando ainda estava em formação no ensino superior. Em muitos casos esse fato se deu em função de não existir profissionais suficientes com formação concluída para assumir as vagas na educação básica.

A maioria dos professores cursou especialização e os professores que cursaram Mestrado estão presentes apenas nas escolas de baixo desempenho, tanto em Curitibanos quanto em Lages. No entanto, não é possível fazer uma análise mais contundente sobre esta (in)existência do mestre na escola de alto desempenho, pois o número é muito pequeno, e talvez este profissional trabalhe isoladamente na perspectiva da pesquisa e da práxis, tão comumente discutida dentro dos programas de stricto sensu do país.

Os fatores que têm interferido no alto ou no baixo desempenho dos alunos na Educação Básica vêm sendo apontados como de diversas ordens. No entanto, só é possível fazer uma análise mais contundente se tivermos um conhecimento da estruturação e do funcionamento da escola e da educação escolar como um todo. Dentro deste contexto a percepção dos professores é fator indispensável na construção de propostas que venham agregar ao movimento de qualificação deste nível de escolarização. Para Barrère apud Tardif e Lessard (2009, p. 172), “a visão dos professores em relação à aprendizagem escolar está articulada a uma incompreensão dos alunos à sua insuficiência de trabalho”.

Com a análise das respostas dos professores, percebeu-se que a maioria tem conhecimento sobre os fatores que contribuem para o alto e o baixo desempenho escolar, demonstrando comprometimento e preocupação com a situação da educação escolar. Outra parte exime-se da sua 
responsabilidade em relação ao aluno, procurando nas interfaces educacionais justificativas para o insucesso desta formação.

Alguns dos fatores mais recorrentes sobre o que é determinante para o alto ou baixo desempenho escolar, estão relacionados à qualidade da prática profissional do professor, nível socioeconômico da família; condições concretas de trabalho dos professores; infraestrutura da escola que o aluno frequenta; escolaridade dos pais; carga horária de atividade pedagógica; início da idade escolar. Estes fatores aparecem na pesquisa, independente do contexto ao qual as escolas estão inseridas.

A partir da análise das respostas abertas, os fatores determinantes foram organizados em categorias. Para os professores das escolas de alto desempenho quatro categorias são fundamentais: estrutura física da escola; gestão escolar; atuação dos professores (aspectos metodológicos); relação família e escola. Por sua vez, as respostas dos professores das escolas de baixo desempenho apontaram para sete categorias: estrutura física da escola; gestão escolar; atuação dos professores (aspectos metodológicos); relação família e escola; além dos aspectos individuais dos alunos; fatores conjunturais externos (contexto socioeconômico e políticas públicas) e fatores pedagógicos.

Segundo a análise das respostas dos professores, observa-se que quatro das categorias consideradas determinantes para o alto desempenho, também se aplicam ao baixo desempenho. As outras três apontadas pelos professores de escolas com baixo desempenho como relevantes evidenciam o contexto sociocultural em que o aluno está inserido, aspectos relacionados à vontade de aprender, à falta/não efetivação de políticas públicas relacionadas à manutenção dos alunos na escola e à rotatividade de professores durante o ano letivo. Sobre o fator da rotatividade, $41 \%$ dos respondentes declararam que houve a inexistência de professores para alguma disciplina no ano de 2010. Para Lapo e Bueno (2003, p. 71), “essa rotatividade gera uma falta de vínculo do professor com a escola, o que pode trazer graves consequências para um tão necessário e almejado ensino de qualidade”.

A categoria Estrutura Física da Escola foi indicada pelos professores de escolas de alto desempenho e baixo desempenho. Para a maioria dos respondentes das escolas de alto desempenho os problemas de aprendizagem não estão relacionados à infraestrutura física e/ou pedagógica (71\%). Das escolas de baixo desempenho este percentual se inverte, $71 \%$ dos respondentes consideram como determinantes os critérios apontados acima. Nas observações in loco constatou-se que embora a maioria das escolas tenha uma estrutura física arejada e bem iluminada, estão em condições ruins de conservação e manutenção, principalmente no que se refere a espaços para 
atividades esportivas, sendo que menos de $20 \%$ das escolas possuem espaço para tal, e material de higiene para os alunos.

A segunda categoria que aparece nas duas dimensões é a Gestão Escolar, subdividida em quatro subcategorias: a) forma de indicação do gestor máximo da escola, b) comprometimento do gestor, c) equipe de apoio pedagógico, d) promoção de formação continuada e permanente na escola.

O papel da direção no contexto escolar é essencial em todas as dimensões do processo administrativo e pedagógico inerentes à escola. Desde a elaboração do PPP até as ações que serão realizadas, as decisões que serão tomadas em prol da implantação do projeto. O gestor, o diretor é um líder e como líder deve mobilizar toda a comunidade escolar em prol dos objetivos educacionais e sociais da escola (DALLAZEM, 2015, p. 96).

Nas escolas participantes do projeto, $100 \%$ das indicações para o cargo de gestores é político-partidária. Portanto, nem sempre o gestor está realmente comprometido com a comunidade na qual a escola está inserida e também, muitas vezes, tem problemas de adaptação com os demais integrantes da equipe diretiva, o que pode refletir negativamente no bom andamento do trabalho do grupo escolar. No entanto, em geral, os professores se sentem valorizados pela direção.

É do diretor da escola a responsabilidade máxima quanto à consecução eficaz da política educacional do sistema e desenvolvimento plenos dos objetivos educacionais, organizando, dinamizando e coordenando todos os esforços nesse sentido e controlando todos os recursos para tal. O Trabalho de um diretor de escola não se limita a ficar sentado atrás de uma mesa, assinando cheques, lidando com prestadores de serviços, fazendo compras, reposição de materiais, etc. (LUCK, 2004, p 32).

Importante observar a resposta dos professores em relação à participação da direção para o bom funcionamento da escola. Observa-se que frequentemente os professores estão satisfeitos com a direção da escola, sentindo-se valorizados pela mesma. Todavia, quando se trata da equipe diretiva há diferença entre escolas de alto e baixo desempenho, sendo que apenas 8\% dos respondentes das escolas de alto desempenho escreveram que o diretor e demais membros da equipe diretiva da escola não colaboram para fazer a escola funcionar bem, em contrapartida mais de 33\% das escolas de baixo desempenho afirmam isso. Com relação a carência de pessoal administrativo também há diferenças significativas. Enquanto nas escolas de alto desempenho somente $4 \%$ dos respondentes afirma que isso causou problemas, nas escolas de baixo desempenho este índice alcançou $44 \%$. 
A atuação dos professores é a terceira categoria que é comum nas respostas dos professores, tanto das escolas de alto e baixo desempenho e contempla três subcategorias: utilização de metodologias atrativas e inovadoras; a busca permanente de iniciativa individual do professor, disponibilização de condições concretas de trabalho (materiais pedagógicos e infraestrutura). Nessa categoria, a presença das subcategorias é, na visão dos professores, determinante para o alto desempenho e a ausência ou a negligência desses aspectos pode levar ao baixo desempenho escolar.

Na pesquisa foram elaboradas vinte questões pertinentes às práticas pedagógicas que os professores desenvolviam com seus alunos e a frequência com que ocorriam. Na cidade de Lages, a diferença é muito significativa, sendo que em média 59,5\% dos professores das escolas de alto desempenho dizem trabalhar estas atividades semanalmente, enquanto em média, apenas 43,3\% dos professores de escolas de baixo desempenho desenvolvem as atividades com a mesma frequência. Essas questões tratam principalmente de atividades que permitem ao aluno discutir as atividades com os professores e de reforçar os conteúdos dominantes para cada assunto.

Isto poderia sugerir que essas atividades realizadas com maior continuidade e acompanhamento reforçam o aprendizado do aluno. No entanto, surge uma inquietação quando analisamos que no caso da cidade de Curitibanos o contexto se inverte, sendo que 64,85\% dos professores dizem trabalhar este acompanhamento com maior frequência são os que trabalham em escolas de baixo desempenho, enquanto $53,41 \%$ dos professores das escolas de alto desempenho realizam estas atividades semanalmente.

Além disso, os professores, em todos os casos, dizem utilizar computador, internet, fitas de vídeo e DVD, jornais e revistas informativas, bem como as em quadrinhos em suas aulas. Poucos utilizam projetor de slides, talvez devido ao fato de as escolas não possuírem o material em quantidade necessária, preferindo utilizar máquina fotocopiadora. Na visão dos alunos de ambos os contextos, há registro desta utilização, no entanto, apenas em algumas aulas, e no caso do uso de computador para redação de textos, isso quase nunca ocorre.

O que chama atenção também é que 100\% dos professores fazem uso do livro de consulta para professores e grande parte utiliza o livro didático para o desenvolvimento de suas atividades. Isso ocorre por mais que na maioria dos casos considerem o material como razoável, não estando plenamente satisfeitos com o mesmo. Mas se não estão satisfeitos não deveriam buscar outras formas de desenvolver o trabalho em sala? O livro didático pode ser um importante orientador para as atividades, mas não deve jamais engessar o processo global de aprendizagem. 
Pelas respostas dos alunos percebeu-se que ainda predomina a metodologia tradicional de repasse de conteúdo com o uso de livro didático (93\% alto e 91\% baixo). Por que os professores insistem em desenvolver este método de aula? Para Vasconcellos (2004),

Quando se pratica a educação tradicional, sendo um método conhecido universalmente, os pais não ousam questionar; qualquer eventual dificuldade é atribuída ao aluno, tanto por parte do professor, quanto por parte dos pais. Trata-se portanto, de uma situação muito confortável, uma vez que não há questionamentos à prática do professor e da escola [...] o professor que tenta inovar, pode ter problemas de disciplina e ainda 'não cumprir o programa (VASCONCELLOS, 2004. p. 28).

Ao serem perguntados sobre a utilização de trabalhos em grupo, para os alunos das escolas de alto desempenho o maior índice aparece “em todas ou quase todas as aulas”, com 43\%. Para os alunos das escolas de baixo desempenho o maior índice aparece “em algumas aulas”, com 50\%. Mas com relação à utilização de jogos e brincadeiras nas aulas os índices ficaram em 50\% para “nunca” em ambas as categorias.

Os alunos das escolas de baixo desempenho de Lages (4,11\% do $9^{\circ}$ ano e $11,95 \%$ do $5^{\circ}$ ano) frequentam menos outros lugares como teatro, museus, exposições e biblioteca com seus professores de português, como forma de trabalho didático, que os alunos das escolas de baixo desempenho de Curitibanos (12,77\% do $9^{\circ}$ ano e $24,66 \%$ do $5^{\circ}$ ano), o que é um dado interessante ao considerarmos que a cidade de Lages tem mais espaços propícios a essas visitações.No entanto, quando tratamos de escolas de alto desempenho, observamos que os dados se invertem, sendo que os alunos de Lages frequentam mais estes espaços (9,44\% do $9^{\circ}$ ano e $24,5 \%$ do $5^{\circ}$ ano) do que alunos das escolas de alto desempenho de Curitibanos (46,11\% do $9^{\circ}$ ano e $17,87 \%$ do $5^{\circ}$ ano).

Outro dado interessante é o fato de os professores de matemática de escolas de alto desempenho utilizarem menos jogos e brincadeiras nas aulas do que as escolas de baixo desempenho, o que sugere que estes professores não costumam diversificar a metodologia de trabalho.

Sequencialmente a isso, na análise da quarta categoria, Relação Família e Escola, duas subcategorias foram evidenciadas: participação da família na escola, apoio e valorização do trabalho da escola. Queiróz (2004, p. 31), aborda um estudo de Brandão et al. (1983), em que “a família foi apontada como um dos determinantes do fracasso escolar da criança, seja pelas suas condições de vida, seja por não acompanhar o aluno em suas atividades escolares”.

[...] a escola deve utilizar todas as oportunidades de contato com os pais, para passar informações relevantes sobre seus objetivos, recursos, problemas e também sobre as 
questões pedagógicas. Só assim, a família irá se sentir comprometida com a melhoria da qualidade escolar e com o desenvolvimento de seu filho como ser humano (PARO, 2000, p. 30).

Quase que por unanimidade, os professores consideram que os possíveis problemas de aprendizagem dos alunos estão relacionados à falta de assistência e acompanhamento da família nos deveres de casa. Conforme discutido anteriormente, os pais dizem acompanhar seus filhos, mas ficou evidente que o maior acompanhamento é para os filhos que estão nas séries iniciais, e que esta assistência é um dos determinantes para o sucesso escolar do aluno.

Os alunos também percebem que esse acompanhamento é maior quando eles são menores. No entanto, pela resposta dos alunos, também se identifica que os professores de escolas de baixo desempenho passam lições para casa em menor periodicidade que os professores de escola de alto desempenho, os quais repassam diariamente estas lições e, no mesmo sentido, ocorre a correção dessas lições e a devolutiva aos alunos.

Para os professores das escolas de baixo desempenho, a categoria Aspectos Individuais dos Alunos foi evidenciada em $100 \%$ dos respondentes e se desmembrou em seis subcategorias: o contexto em que o aluno vive (100\%); falta de hábito de estudos (60\%); indisciplina (100\%); desinteresse do aluno (100\%); baixa autoestima (70\%); baixa motivação (93\%).

A questão da indisciplina também pode ser reflexo de outra informação coletada quando os professores das escolas de Lages dizem não ter ocorrido situações de conflito verbal ou físico entre professores e alunos no último ano na escola, no entanto os conflitos entre alunos é uma constante. Na cidade de Curitibanos estes aparecem em menor número.

Embora não seja em número expressivo, há registro de casos de professores que foram ameaçados por alunos, vítimas de furto, de roubo, alunos que portavam armas brancas em sala ou estavam sob efeito de drogas ilícitas, em todos os casos, não divergindo entre escolas de alto ou baixo desempenho.

O uso de drogas nas escolas tem sido objeto de discussão em diferentes espaços. Leis e projetos de prevenção são criados e implantados, contudo, família e escola parecem se sentir cada vez mais impotentes nesses casos.

Já no que se refere à desmotivação, verifica-se que ela pode ter origem em diferentes contextos, mas o que se pode observar com a pesquisa é que os alunos de escolas de alto desempenho demonstram gostar mais de sua escola, do que os de baixo desempenho, e este pode ser um fator de motivação. 
Da mesma maneira, os alunos de escola de baixo desempenho dizem que os professores incentivam os alunos a participar de atividades da escola, mas que os alunos não querem. E também nessas escolas os alunos se sentem mais acolhidos pelos professores, quando dizem que os mesmos os ajudam sempre quando precisam. Observa-se que, em geral, os alunos se sentem atendidos pelos professores, dizem que eles quase sempre cumprem o que prometem, e estão dispostos a ajudar e também os motivam para que melhorem seu desempenho.

Para os alunos de escolas de baixo desempenho as atividades desenvolvidas em sala são planejadas coletivamente entre alunos e professores, este índice é menor no caso de escolas de alto desempenho, onde os alunos relatam, algumas vezes, não participarem do planejamento.

Quando questionados aos alunos de $9^{\circ}$ ano, em Lages e Curitibanos, sobre o fato de a escola oferecer recuperação para melhorar seus resultados escolares, após suas avaliações, observou-se que as escolas de baixo desempenho têm oferecido mais oportunidade para esta recuperação, do que as escolas de alto desempenho, segundo a resposta dos alunos. Isso confrontaria a hipótese de que quanto maior a possibilidade de revisão e recuperação, maior a propensão a melhoria da aprendizagem e, consequentemente, dos resultados em avaliações externas. Entretanto, não podemos olhar de forma isolada essa informação, pois talvez o número dessa oferta seja maior e a forma como ocorre é que fará realmente a diferença.

A categoria seguinte, Contexto Sociocultural ou fatores externos que interferem no sucesso escolar, aparece intimamente relacionada à categoria dos aspectos individuais dos alunos. Nessa situação ficaram evidenciados quatro indicadores: falta de acesso a materiais de estudo diferenciados (70\%), falta de acesso as tecnologias (87\%), baixa escolaridade dos pais (60\%), falta de perspectiva de futuro (80\%).

Por sua vez, a categoria Políticas Públicas compreende duas subcategorias: valorização do professor e políticas inclusivas. No que se refere à valorização do profissional, não foi evidenciado o fator salarial. Ambos os níveis de respondentes - 70\% (alto) e 67\% (baixo) - discordam de que o baixo salário recebido pelo professor compromete o processo pedagógico. Segundo os professores das escolas de baixo desempenho (67\%), os possíveis problemas de aprendizagem dos alunos estão relacionados à sobrecarga de trabalho que dificulta o planejamento e o preparo das aulas.

Segundo Libâneo, Oliveira e Toschi (2003, p. 345), “O planejamento consiste em ações e procedimentos para tomada de decisões a respeito de objetivos e de atividades a ser realizadas em razão desses objetivos”, assim, se o professor não planeja suas aulas, dificilmente conseguirá atingir 
os seus objetivos com ela, que em geral, perpassa no desejo de tornar o aprendizado do aluno eficaz e consistente.

$\mathrm{Na}$ análise das respostas dos professores observa-se que há uma tendência a se responsabilizar a família e o próprio aluno pelo insucesso escolar e em outros casos o insucesso está relacionado à gestão escolar, à falta de estrutura e equipamentos na escola. São poucas as evidências em que o professor se coloca enquanto fator determinante para o sucesso/insucesso escolar dos seus alunos.

Capellini, Tonelotto e Ciasca (2004) realizaram estudo com o objetivo de comparar o desempenho de escolas em relação à avaliação formal e à opinião de professores sobre os responsáveis pelo sucesso escolar, no qual participaram 164 escolas de ensino fundamental de cidade do interior paulista. De acordo com o estudo realizado, para as autoras, ocorre a rotulação de crianças que apresentam dificuldades de aprendizagem, como incapazes, preguiçosas, lentas e perturbadas, principalmente, no início do período escolar, o que contribui para o agravamento de suas dificuldades, e explicam que:

Tal rotulação, por vezes, decorre da falta de interação existente entre professor-escolafamília, ou seja, o professor identifica o problema de aprendizagem da criança, atribuindo a esta ou à sua família a responsabilidade pelo fracasso escolar, desconsiderando muitas vezes todas as dimensões do processo ensino-aprendizagem (CAPELLINI; TONELOTTO; CIASCA, 2004, s/p).

Os professores, em todos os casos, dizem participar das atividades de formação continuada, bem como dizem usar quase sempre os conhecimentos adquiridos nestas atividades em sua prática em sala de aula.

Ao serem questionados sobre o processo de formação continuada oferecida pelo sistema público de ensino, tanto os professores das escolas de alto como os de baixo desempenho apontaram a necessidade imediata da melhoria nos cursos de formação continuada (100\%). “Acredito que o oferecimento de cursos de formação ainda é muito precário para o professor após a graduação” (resposta do professor participante da pesquisa). Isso demonstra que os sujeitos estão abertos para programas de formação continuada, mas não há relato de professores que buscam esta formação independente da oferta pela escola ou pelas Secretarias de Estado de Educação.

Essa situação é corroborada por Mileo e Kogut (2009) em pesquisa realizada para identificar a influência da formação continuada na prática pedagógica dos professores de Educação Física da rede municipal de Curitiba. Os participantes entendem o sentido da "formação continuada e 
percebem a importância em participar de programas voltados para a atualização profissional, porém, alguns deles, não buscam cursos e momentos, além dos proporcionados pela rede de ensino a qual lecionam” (MILEO; KOGUT, 2009, p. 495).

Outro item que fez parte do questionário foi em relação à participação dos professores no planejamento curricular anual e no Projeto Pedagógico (PP) da escola. O percentual maior, tanto para as escolas de alto e de baixo desempenho, ficou em 33\%, justificando que o PP foi elaborado pelo Diretor e uma equipe de professores. Inclusive um dos comentários dos professores é que este é um documento que não se efetiva no cotidiano da escola.

Para Libâneo, Oliveira e Toschi (2003, p. 345), “O projeto é um documento que propõe uma direção política e pedagógica para o trabalho escolar, formula metas, prevê as ações, institui procedimentos e instrumentos de ação”. Dessa forma, toda a comunidade escolar deveria participar de sua elaboração, discutindo e refletindo sobre os objetivos e resultados esperados.

Na visão dos professores da disciplina de Língua Portuguesa, há uma diferença considerável na capacidade para "resolver situações problemas", com 72\% alto e apenas 25\% para o baixo, assim como no "expressar ideias de forma escrita” (60\% alto e 25\% baixo). Já os professores de matemática, das escolas de baixo desempenho, avaliam que os seus alunos têm melhores capacidades nas operações de adição e subtração (ambas com 62\%) e capacidade menor em fração (37\%). Os professores das escolas de alto desempenho apontam a capacidade de seus alunos em resolução de problemas simples em 80\%, para os problemas mais complexos os índices são menores (fração 52\%; problema 76\%; divisão 66\%; multiplicação 79\%).

Os professores das escolas de alto desempenho garantem que a infraestrutura não influencia no processo de aprendizagem. Em contrapartida, os de baixo desempenho afirmam que este é um fator determinante. Inclusive, apontam que a falta de equipamento e material didático impede a melhoria na qualidade do trabalho docente. No entanto, em ambas as categorias há a utilização do livro didático, conforme discutido anteriormente.

Alguns pais de alunos citam a insegurança dentro da escola como uma preocupação emergente, mas para os professores isto não é critério para justificar o insucesso escolar.

\section{CONSIDERAÇÕES FINAIS}

Embora essa pesquisa tenha permitido traçar um perfil de cada escola participante do projeto e levantar algumas categorias que podem ser determinantes para o alto ou o baixo desempenho, observou-se que não há somente um fator determinante. Várias situações e condições permeiam a 
caminhada dos alunos da educação básica. No caso de Lages e Curitibanos, esses fatores perpassam desde a relação interpessoal dos envolvidos, passando pelo contexto interno e externo à escola, pelas políticas públicas de acesso e inclusão e, ainda, pela conjuntura socioeconômica dos pais.

Embora os Índices de Desenvolvimento da Educação Básica e da Prova Brasil das escolas que compõem o projeto, representem alguns dos índices mais baixos do Estado de Santa Catarina, pode-se perceber que há um comprometimento com a formação dos sujeitos que lá buscam o seu processo de escolarização inicial. As escolas têm efetivamente feito a diferença na maioria das comunidades em que estão inseridas e, em alguns casos, as escolas são a própria referência dessas comunidades. Afinal, pais e alunos reconhecem a importância deste espaço.

Assim, essa pesquisa contribuiu para que a Universidade pudesse compreender ainda mais a importância da articulação entre a formação inicial, continuada e a atuação dos professores na busca da melhoria da qualidade do processo de ensino e aprendizagem.

A pesquisa oportunizou identificar ainda o que professores, alunos e pais consideram como fatores determinantes para o alto e o baixo desempenho de alunos. Um aspecto observado é o descompasso entre a visão que professores têm das suas unidades escolares e suas práticas pedagógicas e como os alunos e pais a percebem. Enquanto o professor assegura que trabalha os conteúdos de forma significativa e dinâmica, nas respostas dos pais e alunos não há indicativos de que isso aconteça.

Observou-se também que nenhum fator, isolado, é determinante para o alto ou o baixo desempenho. Esses fatores perpassam a relação interpessoal dos envolvidos, as políticas públicas, as questões socioeconômicas dos pais e o contexto escolar e comunitário.

Embora as escolas que compõe o projeto, representem alguns dos índices mais baixos do Estado de Santa Catarina (IDEB e Prova Brasil 2009), pode-se perceber que as escolas têm papel preponderante na maioria das comunidades em que estão inseridas e que, em alguns casos, são a própria referência dessas comunidades. Assim, emerge a necessidade de contínua reflexão sobre a formação inicial, continuada e a atuação dos professores na busca da melhoria da qualidade do processo de ensino e aprendizagem. 


\section{REFERÊNCIAS}

ALBERNAZ, Angela; FERREIRA, Francisco; FRANCO, Creso. Qualidade e Equidade na Educação Fundamental Brasileira. Revista Pesquisa e planejamento econômico, PPE, v. 32, n. 3, dez. 2002.

BARRÈRE, Anne. Leslycéensautravail. Paris: PUF, 1997. In: TARDIF, Maurice; LESSARD, Claude. O Ofício de Professor: história, perspectiva e desafios internacionais. 3. ed. Petrópolis: Vozes, 2009.

BRANDÃO, Zaia et al. O estado da arte da pesquisa sobre evasão e repetência no ensino de $1^{\circ}$ grau no Brasil. Revista Brasileira de Estudos Pedagógicos, v. 64, n. 147, p. 38-69, maio/ago. 1983.

CAPELLINI, Simone Aparecida; TONELOTTO, Josiane Maria de Freitas; CIASCA, Syvia Maria. Medidas de desempenho escolar: avaliação formal e opinião de professores. Revista Estudos de Psicologia (Campinas), v. 21, n. 2, Campinas, mai./ago. 2004.

CASARIN, Nelson Elinton Fonseca. Família e aprendizagem escolar. Dissertação (Mestrado em Educação) Programa de Pós-graduação em Educação em Ciências e Matemática, PUCRGS: Porto Alegre, 2007. Disponível em: <http://repositorio.pucrs.br/dspace/bitstream/10923/3004/1/000389091-Texto\%2BCompleto-0.pdf>. Acesso em: 15 mai. 2018.

CHRAIM, Albertina de Mattos. Família e Escola: a arte de aprender para ensinar. Rio de Janeiro: Wak Ed., 2009.

DALLAZEM, Aline. Licenciados em Música: inserção e atuação na educação básica. Curitiba: CRV, 2015.

GUERREIRO-CASANOVA, Daniela Couto; DANTAS, Marilda Aparecida; AZZI, Roberta Gurgel. Autoeficácia de alunos do ensino médio e nível de escolaridade dos pais. Estudos Interdisciplinares em Psicologia, Londrina, v. 2, n. 1, p. 36-55, jun. 2011.

INSTITUTO BRASILEIRO DE GEOGRAFIA E ESTATÍSTICA (IBGE). Disponível em: <http://www.cidades. ibge.gov.br/>.

JACOMINI, Márcia Aparecida. Educar sem reprovar. São Paulo: Cortez, 2010.

LAPO, Flavinês Rebolo; BUENO, Belmira Oliveira. Professores, desencanto com a profissão e abandono do magistério. Cadernos de Pesquisa, n. 118, p. 65-88, mar. 2003.

LIBÂNEO, José Carlos; OLIVEIRA, João Ferreira de; TOSCHI, Mirza Seabra. Educação Escolar: políticas, estrutura e organização. São Paulo: Cortez, 2003.

LUCK, Heloisa. Ação Integrada: Administração Supervisão e Orientação Educacional. 22. ed. Petrópolis: [s.n.], 2004.

MILEO, Thaisa Rodbard; KOGUT, Maria Cristina. A importância da formação continuada do professor de educação física e a influência na prática pedagógica. In: CONGRESSO NACIONAL DE EDUCAÇÃO EDUCERE, IX. Anais... Curitiba: PUCPR, 2009. Disponível em: <http://www.pucpr.br/eventos/educere/ educere2009/anais/pdf>. Acesso em: 24 mai. 2014.

PARO, Vitor Henrique. Qualidade do ensino: a contribuição dos pais. São Paulo: Xamã, 2000.

RAMOS, Lauro; REIS, Mauricio Cortez. A escolaridade dos pais e os retornos à educação no mercado de trabalho. In: Mercado de trabalho - Instituto de Pesquisa Econômica Aplicada, n. 35, fev. 2008. Disponível em: <http://www.ipea.gov.br/agencia/images/stories/PDFs/mercadodetrabalho/04Nota2_35.pdf>. Acesso em: 18 out. 2014.

REZENDE, Wagner Silveira; CANDIAN, Juliana Frizzoni. A família, a escola e o desempenho dos alunos: notas de uma interação cambiante. Disponível em: <http://www.anpae.org.br/iberoamericano2012/Trabalhos/WagnerSilveira Rezende_res_int_GT5.pdf>. Acesso em: 15 out. 2014.

SIMON, Fernanda. Relatório Estatístico da Pesquisa. Campinas: Unicamp, 2013.

VASCONCELLOS, Celso dos Santos.Construção do conhecimento em sala de aula. São Paulo: Libertad, 2004. 


\section{RESUMO}

Esta pesquisa investigou quais fatores podem ser determinantes e/ou condicionantes do baixo e alto desempenho escolar, tendo como base a Prova Brasil e o Censo Escolar de 2009. Para a coleta de dados utilizou-se questionários para alunos, pais, professores e observação in loco das escolas. Foram realizadas análises quali-quantitativas dos dados levantados. Na relação família e escola a investigação permeou a composição socioeconômica da família e as suas expectativas em relação aos processos pedagógicos na escola. Na relação professores e alunos evidenciaram-se as categorias: estrutura física, gestão escolar, atuação dos professores, relação família e escola, contexto sociocultural e políticas públicas.

Palavras-chave: Avaliação de desempenho. Educação Escolar. Família e Escola.

\section{THE SCHOOL PERFORMANCE IN THEVOICEOFACTORSOFPUBLIC CATARINENSESSCHOOLS}

\section{ABSTRACT}

This research investigated which factors maybe determinants and/or constraints of low and high school performance, basedon Prova Brasil and the School Census of 2009. For information collection, questionnaires were used for students, parents, and teachers and in loco observation of schools. Qualitative and quantitative analyzes of the data were performed. In the family and school relationship, the investigation permeated the socioeconomic composition of the family and their expectations regarding the pedagogical processes in the school. In the relationship between teachers and students, there were the categories: Physical Structure, School Management, Teachers' performance, Family and School Relations, Sociocultural Contextand Public Policies.

Keywords: Performance evaluation. Schooling. Family andSchool.

\section{EL DESEMPEÑO ESCOLAR EN LA VOZ DE LOS ACTORES DE ESCUELAS PÚBLICAS CATARINENSES}

\section{RESUMEN}

Esta investigación investigo qué factores pueden ser determinantes y/o condicionantes del bajo y alto desempeño escolar, teniendo como base La Prueba Brasil y el Censo Escolar de 2009. Para La recolección de datos se utilizaron cuestionarios para alumnos, padres, profesores y observación in de Las escuelas. Se realizaron análisis cuantitativos de los datos levantados. Enlarelación familia y escuela La investigación permeó La composición socioeconómica de lafamilia y sus expectativas em relación a los procesos pedagógicos em La escuela. Em La relación profesores y alumnos se evidenciaron lãs categorías: estructura física, gestión escolar, actuación de los profesores, relación familia y escuela, contexto sociocultural y políticas públicas.

Palabras-clave: Evaluación de rendimiento. Educación Escolar. Familia y Escuela. 